\title{
Envionmental Impacts of Mesoporous Silver-Supported Cobalt Oxide Catalyst Based on Life Cycle Assessment
}

\author{
Xueying Li ${ }^{1}$, Bingyang Bai ${ }^{1 \text {, *, Yupeng } \text { Fan }^{2} \text {, Minghui Xie }}{ }^{1}$, Qi Qiao ${ }^{1}$, \\ ${ }^{1}$ Key Laboratory of Eco-Industry of the Ministry of Ecology and Environment, Chinese Research Academy of Environmental Sciences, Beijing, \\ China \\ ${ }^{2}$ Institute of Geographic Sciences and Natural Resources Research, Chinese Academy of Sciences, Beijing, China
}

Email address:

baibingyang@tsinghua.org.cn (Bingyang Bai), qiaoqi@craes.org.cn (Qi Qiao)

*Corresponding author

To cite this article:

Xueying Li, Bingyang Bai, Yupeng Fan, Minghui Xie, Qi Qiao. Envionmental Impacts of Mesoporous Silver-Supported Cobalt Oxide Catalyst Based on Life Cycle Assessment. International Journal of Environmental Protection and Policy. Vol. 6, No. 4, 2018 , pp. $71-77$. doi: $10.11648 /$ j.ijepp.20180604.11

Received: September 6, 2018; Accepted: September 28, 2018; Published: October 27, 2018

\begin{abstract}
Life cycle assessment can be used to evaluate the environmental issues involved in the entire product production process (including raw material acquisition, production, transportation, use/maintenance and final disposal). It is an important support tool for screening and developing an efficient, low-cost and environmentally friendly product. In this study, based on the life cycle method, an environmental impact assessment of the resource consumption and pollutant emission data was carried out for the mesoporous $\mathrm{K}-\mathrm{Ag} / \mathrm{Co}_{3} \mathrm{O}_{4}$ catalyst life cycle. The results show that the proportion of resource consumption to produce $1 \mathrm{~kg}$ of mesoporous $\mathrm{K}-\mathrm{Ag} / \mathrm{Co}_{3} \mathrm{O}_{4}$ is 0.132 . Environmental impact types mainly contain fossil depletion, climate change, human health and particulate matter formation; The substances produced by mesoporous $\mathrm{K}-\mathrm{Ag} / \mathrm{Co}_{3} \mathrm{O}_{4}$ catalyst life cycle have the greatest impact on human health, including carcinogens, resp. inorganics and human toxicity. These substances are mainly gas pollutants, $\mathrm{CO}_{2}$ emission is the largest, followed by $\mathrm{SO}_{2}$ and $\mathrm{CH}_{4}$. Whether it is health impact, environmental impact or resource depletion, electricity consumption is the main factor. Thus, it is necessary to improve the production process and use low-power equipment to reduce the environmental impact of the entire life cycle. The use of mesoporous $\mathrm{K}-\mathrm{Ag} / \mathrm{Co}_{3} \mathrm{O}_{4}$ catalyst has purified a large amount of formaldehyde and has a good environmental effect.
\end{abstract}

Keywords: Life Cycle Assessment, Environmental Impact Assessment, Mesoporous K-Ag/ $\mathrm{Co}_{3} \mathrm{O}_{4}$, Power, Gas Pollutants

\section{Introduction}

With the development of modern science and technology, technology evaluation has become an indispensable method of technology selection and is an important part of the management of science and technology. Technology evaluation methods include the linear weighting method, analytic hierarchy process (AHP), principal component analysis (PCA), fuzzy comprehensive evaluation method, life cycle assessment (LCA), and others. The principle of the linear weighting method is simple, but it is difficult to choose the appropriate unified quantification means [1]. AHP has two obvious shortcomings. First, the judgment matrix of AHP is established by experts, which results in a certain degree of subjectivity with AHP. Second, AHP is a single comparison of each index of each scheme but does not consider their correlation [2]. PCA has the function of decreasing the dimensionality and removing the correlation, but the data that it contains are not comprehensive, and it is likely that data will be lost during the analysis [3]. The fuzzy comprehensive evaluation method is easy to grasp. It can be used to quantify some objects that are not clear and difficult to quantify, but the weights of the evaluation factor value with prior uncertainty may lead to biased evaluation results [4].

LCA is an important tool to support product-oriented environmental management. Not only can it carry out the quantitative analysis and evaluation of effective current environmental conflicts, but it can objectively and comprehensively evaluate the environmental issues involved throughout the product lifespan, "from cradle to grave" [5]. 
Walser et al [6] performed LCA to compare nanosilver T-shirts with conventional T-shirts, with and without biocidal treatment. The results showed that consumer behavior markedly affects the environmental impacts during the use phase. Lower washing frequencies can compensate for the increased climate footprint of FSP nanosilver T-shirt production. The production phase may be rather significant due to toxic silver emissions at the mining site, if high silver quantities are required. Hong and $\mathrm{Xu}$ [7] carried out LCA using IMPACT2002+ to estimate the environmental impacts of caprolactam production in China. The technology contributed significantly to the potential impacts of carcinogens, respiratory inorganic matters, global warming, and non-renewable energy. The key to reducing these impacts is to use natural gas power generation and improve the efficiency of the $\mathrm{NO}_{\mathrm{x}}$ and ammonia emission control system.

At present, there very few whole process evaluations and product environmental impact analyses of VOCs purification catalysts, and they cannot provide management support services for China's environmental protection industry, especially the VOCs purification industry. Common industrial VOCs treatment technologies include adsorption, condensation and membrane separation for VOCs recovery and combustion, plasma treatment, photocatalytical degradation and bio-degradation for VOCs destruction [8]. Catalytic combustion has many advantages, such as a wide range of applications, simple equipment, and no secondary pollution. It is the main choice for the industrial purification of VOCs. The core of the technology is the catalyst products. Kaluž et al. [9] prepared $\mathrm{Mo} / \mathrm{ZrO}_{2}$ and $\mathrm{CoMo} / \mathrm{ZrO}_{2}$ catalysts by impregnating the monoclinic $\mathrm{ZrO}_{2}$ with the chelating agent, nitrilotriacetic acid (NTA), assisted by the spreading of $\mathrm{MoO}_{3}$ with $\mathrm{CoCO}_{3}$, or $\left(\mathrm{NH}_{4}\right)_{6} \mathrm{Mo}_{7} \mathrm{O}_{24} \cdot 4 \mathrm{H}_{2} \mathrm{O}$ with $\mathrm{Co}\left(\mathrm{NO}_{3}\right)_{2} \cdot 6 \mathrm{H}_{2} \mathrm{O}$. The optimal molar ratio $\mathrm{NTA} /(\mathrm{Co}+\mathrm{Mo})$ to achieve high hydrodesulphurization activities was $1 / 1$. Liu et al. [10] studied the use of Pt-Rh-Pd alloy gauze catalysts for ammonia oxidation to improve the efficiency of nitric acid in the industry and proposed a catalytic mechanism of the gauze catalysts based on their characterization by FESEM and EDS. As a result, the catalytic effect is improved by $1 \%$, the cost is reduced by $30 \%$ and the loss of $\mathrm{Pt}$ is decreased from $120 \mathrm{mg}$ to $70 \mathrm{mg}$. Bai and $\mathrm{Li}$ [11] prepared mesoporous a $\mathrm{K}-\mathrm{Ag} / \mathrm{Co}_{3} \mathrm{O}_{4}$ catalyst by selecting $\mathrm{K}+$ as additives on the basis of the $\mathrm{Ag} / \mathrm{Co}_{3} \mathrm{O}_{4}$ catalyst. The addition of $\mathrm{K}^{+}$obviously promoted the interaction between $\mathrm{Ag}$ and $\mathrm{Co}$, produced more of the surface lattice oxygen species, and enhanced the activity of formaldehyde oxidation.

Based on LCA, researchers have carried out environmental impact analyses and established LCA databases for approximately 16 industries, such as metal [12], buildings [13], electronic devices [13] and textiles [15]. These data and analyses can provide a scientific basis and technical support for formulating industry environmental management indicators and cleaner production management. However, promising catalysts have not yet been used in the LCA study. This research selected a mesoporous $\mathrm{K}-\mathrm{Ag} / \mathrm{Co}_{3} \mathrm{O}_{4}$ catalyst for VOCs purification, studied its entire life-cycle environmental impact by LCA to establish the LCA basic data of the mesoporous $\mathrm{K}-\mathrm{Ag} / \mathrm{Co}_{3} \mathrm{O}_{4}$ catalyst and analyzed the environmental influence of the entire life-cycle. We provide a technical reference for improving the clean production management of the VOCs purification industry.

\section{Materials and Methods}

\subsection{LCA Scope and Functional Unit Determination}

The purpose of this study is to evaluate the life cycle environmental impact of the mesoporous $\mathrm{K}-\mathrm{Ag} / \mathrm{Co}_{3} \mathrm{O}_{4}$ catalyst and identify the phases with poor environmental performance to improve the environmental performance of the catalyst. The functional unit in this research is the production of $1 \mathrm{~kg}$ of mesoporous $\mathrm{K}-\mathrm{Ag} / \mathrm{Co}_{3} \mathrm{O}_{4}$ catalyst. The system boundary of this LCA is shown schematically in Figure 1. This boundary defines a "cradle-to-grave" analysis and includes the chemical transport, mesoporous $\mathrm{K}-\mathrm{Ag} / \mathrm{Co}_{3} \mathrm{O}_{4}$ catalyst production, transportation, use and final treatment.

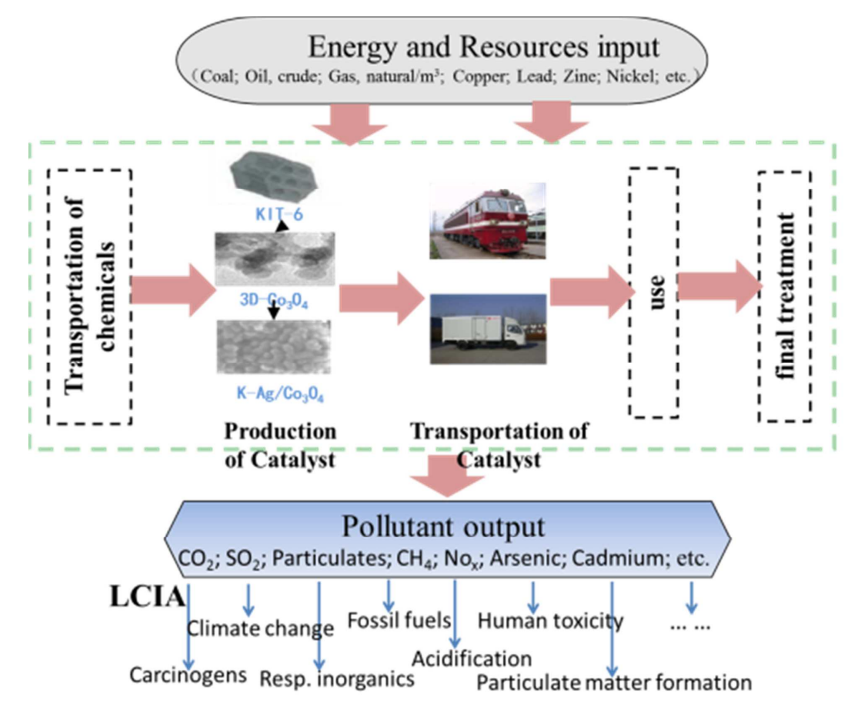

Figure 1. System boundary of mesoporous $\mathrm{K}-\mathrm{Ag} / \mathrm{CO}_{3} \mathrm{O}_{4}$ catalyst.

The equipment used to produce $1 \mathrm{~kg}$ of mesoporous $\mathrm{K}-\mathrm{Ag} / \mathrm{Co}_{3} \mathrm{O}_{4}$ can be used in many other processes. This production had little impact on the equipment, ignoring the environmental impact of equipment production and use [16]. Since all chemicals were transported in a similar manner, the transport phase of the chemical was excluded. Therefore, this study mainly considered the production, transportation, use and final treatment of mesoporous $\mathrm{K}-\mathrm{Ag} / \mathrm{Co}_{3} \mathrm{O}_{4}$.

\subsection{Life Cycle Inventory Analysis of Mesoporous $\mathrm{K}-\mathrm{Ag} / \mathrm{Co}_{3} \mathrm{O}_{4}$ Catalyst}

\subsubsection{The Proution Phase of Mesoporous $-\mathrm{Ag} / \mathrm{Co}_{3} \mathrm{O}_{4}$ Catalyst}

Due to the fact that the mesoporous $\mathrm{K}-\mathrm{Ag} / \mathrm{Co}_{3} \mathrm{O}_{4}$ catalyst has not been industrialized yet, the inventory data in this phase mainly uses the combination of laboratory data and 
industrial production data to make the life cycle assessment of catalyst products more accurate. Among them, the consumption data of raw materials mainly come from the linear increase of laboratory data (according to the conservation of materials, we can see that the use of raw materials has nothing to do with the scale, the loss of raw materials of large equipment may change, but it has little effect). The power data involved mainly come from The same process of business data. Mesoporous $\mathrm{K}-\mathrm{Ag} / \mathrm{Co}_{3} \mathrm{O}_{4}$ catalyst is synthesized by using KIT-6 molecular sieve as hard template and ethanol as dispersant. On the basis of $3 \mathrm{D}-\mathrm{Co}_{3} \mathrm{O}_{4}, \mathrm{~K}+$ and $\mathrm{Ag}$ nanoparticles are loaded. The content of $\mathrm{K}$ is $1.7 \%$, and the content of $\mathrm{Ag}$ is $6.4 \%$. The production phase list data is shown in Table 1.

Table 1. The inventory data of production stage.

\begin{tabular}{lll}
\hline Name & Quantity & Unit \\
\hline $\mathrm{P} 123$ & 2.47 & $\mathrm{~kg}$ \\
$30 \% \mathrm{HCl}$ & 5.80 & $\mathrm{~kg}$ \\
deionized water & 280.00 & $\mathrm{~kg}$ \\
$\mathrm{~N}-$ butanol & 2.36 & $\mathrm{~kg}$ \\
TEOS & 2.36 & $\mathrm{~kg}$ \\
ethanol & 13.62 & $\mathrm{~L}$ \\
$\mathrm{NaOH}$ & 37.00 & $\mathrm{~kg}$ \\
$\mathrm{Co}\left(\mathrm{NO}_{3}\right)_{2} \cdot 6 \mathrm{H}_{2} \mathrm{O}$ & 3.33 & $\mathrm{~kg}$ \\
$\mathrm{~K}_{2} \mathrm{CO}_{3}$ & 0.68 & $\mathrm{~kg}$ \\
$\mathrm{AgNO}$ & 98.04 & $\mathrm{~g}$ \\
$\mathrm{NH}_{3} \cdot \mathrm{H}_{2} \mathrm{O}$ & 13.91 & $\mathrm{~L}$ \\
electricity & 1.30 & $\mathrm{MWh}$ \\
\hline
\end{tabular}

\subsubsection{The Transportation Phase of Mesoporous}

This study assumes that all the catalysts are used in China's VOCs purification industry and are not exported from abroad. The transport distance and transport mode were estimated by freight volume and average distance of the various modes of transport in 'Statistical Communique on the 2016 National Economic and Social Development in China', as shown in Table 2.

Table 2. The volume of goods and transport distance of various modes of transport.

\begin{tabular}{lllll}
\hline Modes of transport & $\begin{array}{l}\text { Rail } \\
\text { way }\end{array}$ & $\begin{array}{l}\text { High } \\
\text { way }\end{array}$ & $\begin{array}{l}\text { Water } \\
\text { way }\end{array}$ & $\begin{array}{l}\text { civil } \\
\text { aviation }\end{array}$ \\
\hline volume of goods $/ \mathrm{kg}$ & 0.0769 & 0.776 & 0.147 & 0.000154 \\
transport distance $/ \mathrm{km}$ & 714 & 182 & 1500 & 3315 \\
\hline
\end{tabular}

\subsubsection{The Use Phase of Mesoporous $\mathrm{K}-\mathrm{Ag} / \mathrm{Co}_{3} \mathrm{O}_{4}$ Catalyst}

The mesoporous $\mathrm{K}-\mathrm{Ag} / \mathrm{Co}_{3} \mathrm{O}_{4}$ catalyst is mainly used in the field of VOCs purification. In this stage, formaldehyde purification is taken as an example to study the catalytic performance of the mesoporous $\mathrm{K}-\mathrm{Ag} / \mathrm{Co}_{3} \mathrm{O}_{4}$ catalyst. The formaldehyde conversion of mesoporous $\mathrm{K}-\mathrm{Ag} / \mathrm{Co}_{3} \mathrm{O}_{4}$ catalyst was $50 \%$ at room temperature $\left(25^{\circ} \mathrm{C}\right)$ and space velocity of $30000 \mathrm{~h}-1$. The service life of the catalyst is two years, a total of $26280 \mathrm{~kg}$ can be purified formaldehyde. $38544 \mathrm{~kg} \mathrm{CO}_{2}$ is generated during use.

2.2.4. The Final Phase of Mesoporous $\mathrm{K}-\mathrm{Ag} / \mathrm{Co}_{3} \mathrm{O}_{4}$ Catalyst With the use of mesoporous $\mathrm{K}-\mathrm{Ag} / \mathrm{Co}_{3} \mathrm{O}_{4}$ catalyst, the $\mathrm{H}_{2} \mathrm{~S}$ and $\mathrm{NH}_{4}+$ in the air would cause the catalyst to be poisoned and the activity decreased. This kind of inactivation is often difficult to recover simply. Although it is renewable, the regenerative effect is not ideal, and it still needs to be replaced within a certain period. Therefore, the mesopore $\mathrm{K}-\mathrm{Ag} / \mathrm{Co}_{3} \mathrm{O}_{4}$ catalyst is no longer regenerated after deactivation, recycled directly through the downstream base chemical production enterprises. The Ag was separated by adding hydrochloric acid to produce silver chloride and then extracted with anhydrous ethanol to extract cobalt chloride and potassium chloride as a basic chemical. This stage needs to consume $4.4 \mathrm{~kg} 30 \% \mathrm{HCl}$ and $3 \mathrm{~kg}$ ethanol, discharge $0.3 \mathrm{~kg}$ $\mathrm{Cl} 2$.

\subsubsection{Life Cycle Resource Consumption and Environmental Emissions Inventory Analysis of Mesoporous $\mathrm{K}-\mathrm{Ag} / \mathrm{Co}_{3} \mathrm{O}_{4}$ Catalyst}

According to the GB/T 24040-2008 "Environmental Management Life Cycle Assessment Principles and Framework" and the goal and the scope of this study, we used SimaPro software to aid in the analysis of inventory, collected and analyzed the mesoporous $\mathrm{K}-\mathrm{Ag} / \mathrm{Co}_{3} \mathrm{O}_{4}$ life cycle resource consumption and environmental emissions data. Each process in SimaPro has two versions: the unit process and the system process. This study adopted the system process, where the emissions of each process of the life cycle were recorded in the process. The data mainly comes from the Ecoinvent database in Switzerland. The power data uses the resource consumption and environmental emissions data generated by Chinese power plants. The proportion of resource consumption in producing $1 \mathrm{~kg}$ of mesoporous $\mathrm{K}-\mathrm{Ag} / \mathrm{Co}_{3} \mathrm{O}_{4}$ is 127.4 of the per capita resource consumption after standardization, and the resource consumption is mainly concentrated in the mesoporous $\mathrm{K}-\mathrm{Ag} / \mathrm{Co}_{3} \mathrm{O}_{4}$ production stage, accounting for $97 \%$ of the total resource consumption. Overall, the power consumption caused by the muffle furnace, ovens and other equipment in the production process accounted for $68.6 \%$ of resource consumption. The percentage of standardized consumption of the total consumption is shown in Figure 2. The substance emission inventory is shown in Table 3.

Figure 2 illustrates that the greatest consumption of energy in the mesoporous $\mathrm{K}-\mathrm{Ag} / \mathrm{Co}_{3} \mathrm{O}_{4}$ catalyst life cycle after standardization is coal, accounting for $42 \%$ of the total energy consumption. This is mainly due to China's major power source being coal-fired power generation. The high consumption and low efficiency of coal combustion patterns emit large amounts of $\mathrm{SO}_{2}, \mathrm{CO}_{2}$ and soot into the air, causing severe air contamination, which is dominated by soot. Therefore, shifting China's power generation structure and using cleaner fuels, such as gas and solar energy to generate electricity are particularly important to reduce air pollution. Second, the consumption of oil, natural gas and off-gas in mines accounts for $23 \%, 15 \%$ and $14 \%$, respectively. The off-gas in mines include the $\mathrm{CH}_{4}$ and $\mathrm{CO}$ produced during coal mining, which realizes the recycling of waste gas and reduces air pollution. 
Table 3. Environmental emission inventory of mesoporous $\mathrm{K}-\mathrm{Ag} / \mathrm{Co}_{3} \mathrm{O}_{4}$.

\begin{tabular}{llllll}
\hline Emission material & Total/kg & \multicolumn{4}{l}{ The proportion of pollution emissions in all stages/\% } \\
\hline & & Production phase & Transportation phase & Use phase & Final phase \\
\hline Arsenic & & 99.991 & 0.0004 & 0 & 0.0083 \\
Cadmium & 0.0077 & 99.984 & 0.0005 & 0 & 0.0157 \\
Carbon dioxide & 0.0028 & 0.0059 & 0 & 99.979 & 0.0154 \\
Carbon dioxide, fossil & 38552 & 99.999 & 0.0006 & 0 & $3.5 \mathrm{E}-05$ \\
Chromium & 4607.1 & 99.992 & 0.0015 & 0 & 0.0061 \\
Formaldehyde & 0.0015 & $-1.4 \mathrm{E}-05$ & $-8.5 \mathrm{E}-10$ & 100 & $-1.8 \mathrm{E}-07$ \\
Lead & -26280 & 99.982 & 0.0012 & 0 & 0.0168 \\
Methane, fossil & 0.0058 & 100.00 & $0.5 \mathrm{E}-05$ & 0 & 0 \\
Nickel & 35.326 & 99.995 & 0.0004 & 0 & 0.0044 \\
Nitrogen oxides & 0.0813 & 99.994 & $9.0 \mathrm{E}-05$ & 0 & 0.0043 \\
Particulates & 16.867 & 99.999 & $8.8 \mathrm{E}-05$ & 0 & 0.0004 \\
Sulfur dioxide & 57.856 & 99.986 & 0.0008 & 0 & 0.0142 \\
Zinc & 54.881 & 99.995 & & 0 & 0.0042 \\
\hline
\end{tabular}

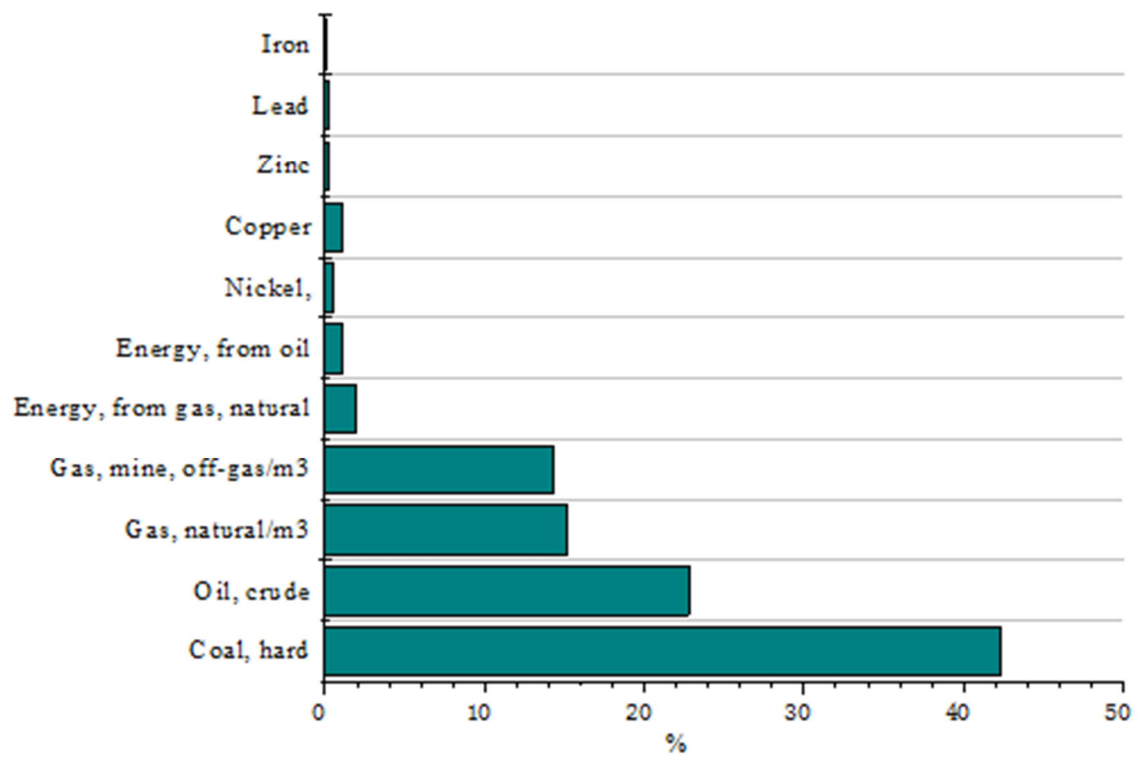

Figure 2. The percentage of standardized consumption of the total consumption.

As shown in Table 3, in addition to $\mathrm{CO}_{2}$, the mesoporous $\mathrm{K}-\mathrm{Ag} / \mathrm{Co}_{3} \mathrm{O}_{4}$ catalyst life cycle emissions come primarily from the mesoporous $\mathrm{K}-\mathrm{Ag} / \mathrm{Co}_{3} \mathrm{O}_{4}$ production stage. The highest contributor to consumption in the production process is coal, whereas the dry flue gases produced by the complete combustion of coal are mainly $\mathrm{CO}_{2}, \mathrm{SO}_{2}$ and $\mathrm{N}_{2}$. The soot produced consists mainly of black smoke and fly ash, and these two substances occur in the form of particulate matter. Oil and natural gas are the main raw materials for producing ethanol and ammonia. Oil is mainly hydrocarbons, and $85 \%$ of natural gas is composed of methane. Therefore, the largest emissions in the air are $\mathrm{CO}_{2}$, followed by $\mathrm{SO}_{2}$, particulates and $\mathrm{CH}_{4}$. The pollutants that are discharged into the water are mainly arsenic and cadmium. The use of mesoporous $\mathrm{K}-\mathrm{Ag} / \mathrm{Co}_{3} \mathrm{O}_{4}$ catalyst purifies a large amount of formaldehyde, resulting in $99.97 \%$ of $\mathrm{CO}_{2}$. In the transport and recovery stages, the emission of pollutants is less, and it is basically negligible. $\mathrm{CO}_{2}$ and $\mathrm{CH}_{4}$ are major greenhouse gases that will gradually increase the temperature of the earth's surface. The greenhouse effect of $\mathrm{CH}_{4}$ is 25 times greater than that of $\mathrm{CO}_{2}$ [17]. $\mathrm{SO}_{2}$ not only reacts in the atmosphere to form sulfuric acid rain but also reacts with alkaline ions such as $\mathrm{Ca}^{2+}$ and $\mathrm{NH}_{4}{ }^{+}$to produce sulfate and form inorganic fine particles [18]. NOx combines with water vapor in the atmosphere to form nitric acid fog and then to form nitric acid rain. Under light conditions, NOx will react with VOCs to form organic fine particles and increase ground ozone concentration [19] and can react with alkali ions to generate nitrate and then form fine particles.

\subsection{Life Cycle Environmental Impact Assessment (LCIA)}

LCIA is the stage in which the importance and significance of product potential environmental impact can be understood and evaluated and is the core part of a life cycle assessment. The LCIA result is heavily dependent on the use of impact assessment methods, which differ in the scientific models that are used to convert emission inventories into comparable environmental impact loads [20]. The impact assessment consists of three steps: classification, characterization and weighted evaluation. Eco-indicator 99 divides 11 different types of impact indicators into three categories: the first is the effects on human health, including climate change, ozone 
layer, carcinogens, respiratory and radiation; the second is the ecosystem quality, including ecotoxicity, land use, acidification/eutrophication; and the third is resources depletion, including minerals and fossil fuels [21].

As shown in Figure 3, by using the ReCiPe Endpoint and Eco-indicator 99 methods to standardize the mesoporous $\mathrm{K}-\mathrm{Ag} / \mathrm{Co}_{3} \mathrm{O}_{4}$ life cycle emission inventory data, and then weighte [22], we calculate the environmental impact load of each environmental impact category to avoid the loss of important parameters caused by the mismatch between the data and the impact assessment list. Data standardization has two objectives: the first is to provide a comparable standard for the relative sizes of various impact types, thus comparing the contribution sizes of various impact types, and the second is to provide evidence for further evaluation. The potential environmental impact is thus comparable and reflects the impact types' relative importance after weighting [23].

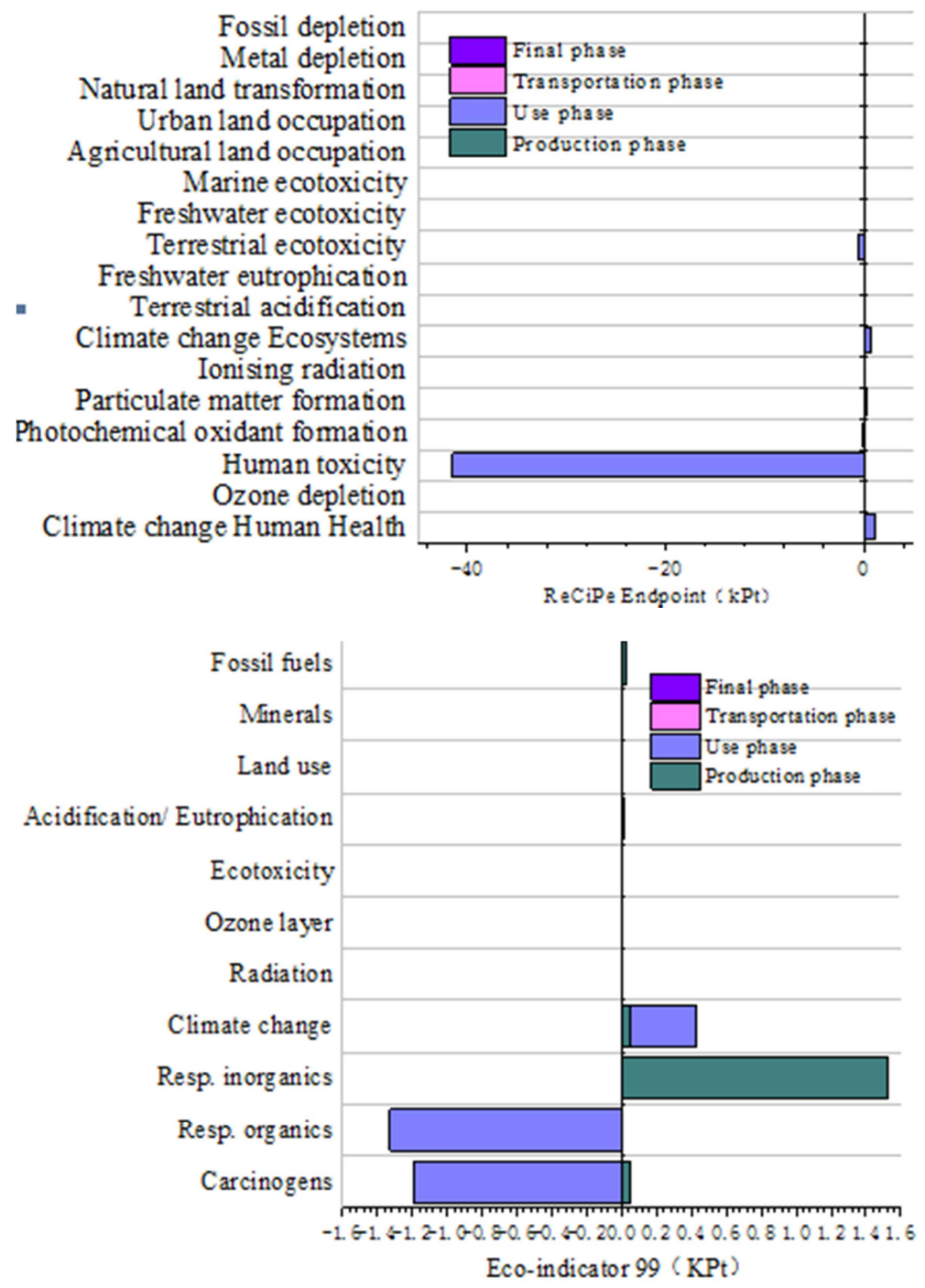

Figure 3. Comparison of environmental impact loads of different environmental impact types, based on two environmental assessment methods.

From Figure 3, we can see that the use of mesoporous $\mathrm{K}-\mathrm{Ag} / \mathrm{Co}_{3} \mathrm{O}_{4}$ catalyst effectively removed formaldehyde and greatly reduced the harm of formaldehyde to human body, including carcinogenesis, resp. organics and human toxicity. The result shows that the major environmental effects of the pollutants are on climate change, fossil depletion, particulate matter formation and resp. inorganics. Considering synthetically, though a small amount of pollutants will be produced during the whole life cycle of the mesoporous $\mathrm{K}-\mathrm{Ag} / \mathrm{Co}_{3} \mathrm{O}_{4}$ catalyst, which will adversely affect the respiratory tract and climate of the human body, a large amount of formaldehyde is purified in the use stage. If the formaldehyde is discharged into the atmosphere, the environmental damage caused is far greater than that caused by the pollutants generated during the entire life cycle of the mesoporous $\mathrm{K}-\mathrm{Ag} / \mathrm{Co}_{3} \mathrm{O}_{4}$ catalyst. Therefore, the mesoporous $\mathrm{K}-\mathrm{Ag} / \mathrm{Co}_{3} \mathrm{O}_{4}$ catalyst has a good environmental effect, which is industrially applicable.

Table 3 shows that, except for $\mathrm{CO}_{2}$, the material of the mesoporous $\mathrm{K}-\mathrm{Ag} / \mathrm{Co}_{3} \mathrm{O}_{4}$ life cycle mainly comes from the production stage of mesoporous $\mathrm{K}-\mathrm{Ag} / \mathrm{Co}_{3} \mathrm{O}_{4}$, while the $\mathrm{CO}_{2}$ generated during the use stage is mainly produced by the catalytic oxidation of formaldehyde. According to the material balance, we can see that it cannot be reduced. Therefore, in 
order to improve the environmental impact of the mesoporous $\mathrm{K}-\mathrm{Ag} / \mathrm{Co}_{3} \mathrm{O}_{4}$ catalyst, we analyzed the environmental impact load of each link in the production stage. The result is shown in Figure 4.

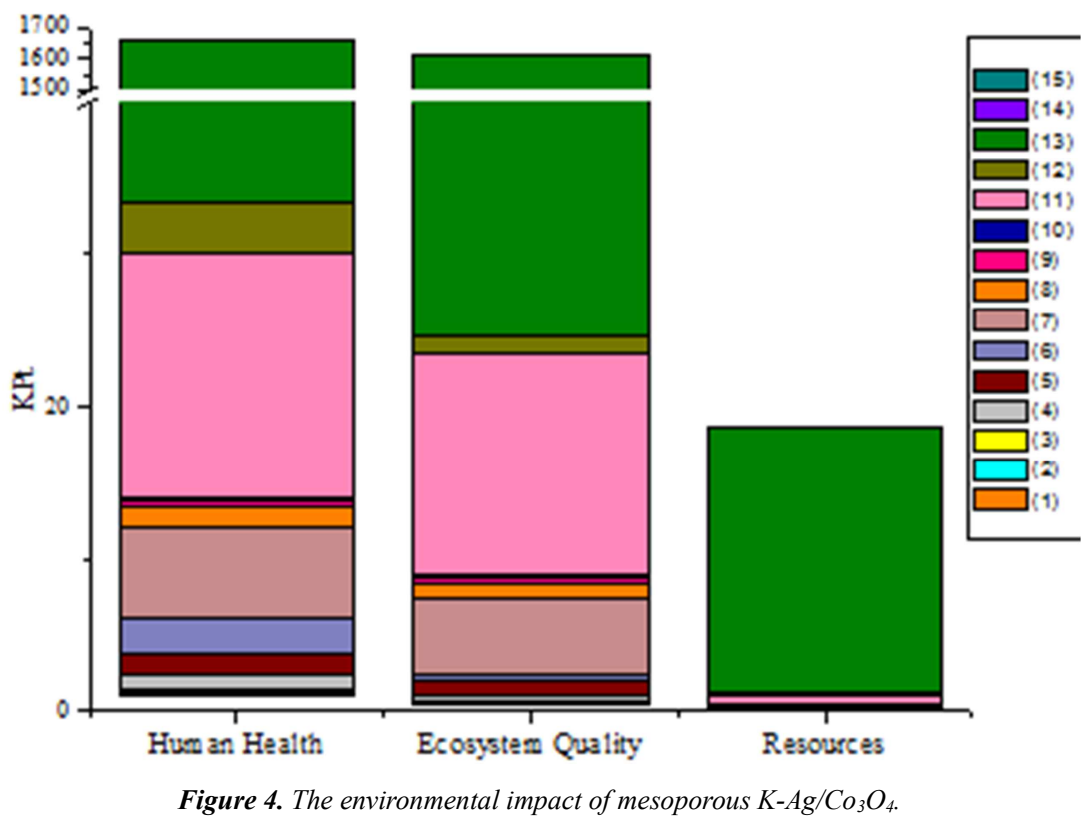

(1) P123, (2) HCl, (3) De-ionized water, (4) 1-butanol, (5) Tetraethyl orthosilicate, (6) Ethanol, (7) $\mathrm{NaOH}$, (8) Cobalt, (9) $\mathrm{HNO}_{3}$, (10) $\mathrm{K}_{2} \mathrm{CO}_{3}$, (11) Silver, (12) Ammonia, (13) Electricity, (14) Transport, freight train, (15) Transport, freight, lorry

Figure 4 shows that the pollutants produced by the life cycle of mesoporous $\mathrm{K}-\mathrm{Ag} / \mathrm{Co}_{3} \mathrm{O}_{4}$ have a great influence on human health. The greatest impact on human health, environment and resource depletion is power consumption. Therefore, it is particularly important to prepare a resource-saving catalyst by reducing the power consumption, which can be realized by improving the production process of the catalyst and ameliorating the performance of equipment. In addition to power consumption, the consumption of silver and $\mathrm{NaOH}$ has the greatest impact on human health and the environment.

\section{Result and Discussion}

(1) The proportion of resource consumption in producing 1 $\mathrm{kg}$ of mesoporous $\mathrm{K}-\mathrm{Ag} / \mathrm{Co}_{3} \mathrm{O}_{4}$ catalyst is 0.132 of the total per capita resource consumption, and the resource consumption is mainly concentrated in the mesoporous $\mathrm{K}-\mathrm{Ag} / \mathrm{Co}_{3} \mathrm{O}_{4}$ production stage, accounting for $97 \%$ of the total resource consumption. Therefore, to reduce the total resource consumption, scientific research and development should be carried out to find low-energy chemicals to substitute for surfactants, n-butanol and other high-consumption resources.

(2) The largest emissions in the air are $\mathrm{CO}_{2}$, followed by $\mathrm{SO}_{2}$, particulates and $\mathrm{CH}_{4}$. The pollutants discharged into the water are mainly arsenic and cadmium. $\mathrm{CO}_{2}$ and $\mathrm{CH}_{4}$ are greenhouse gases and the main sources of climate warming. With the rapid development of the economy, the content of $\mathrm{CO}_{2}$ in the atmosphere is gradually increasing, and the contribution rate to global warming can reach $50 \%-60 \%$. $\mathrm{SO}_{2}$ not only reacts in the atmosphere to form sulfuric acid rain, but it also reacts with alkaline ions, such as $\mathrm{Ca}^{2+}$ and $\mathrm{NH}_{4}^{+}$, to produce sulfate and form inorganic, fine particles. NOx combines with water vapor in the atmosphere to form nitric acid fog, and it then forms nitric acid rain. Under light conditions, NOx will react with VOCs to form organic fine particles and increase ground ozone concentration.

(3) Though a small amount of pollutants will be produced during the whole life cycle of the mesoporous $\mathrm{K}-\mathrm{Ag} / \mathrm{Co}_{3} \mathrm{O}_{4}$ catalyst, which will adversely affect the respiratory tract and climate of the human body, a large amount of formaldehyde is purified in the use stage. If the formaldehyde is discharged into the atmosphere, the environmental damage caused is far greater than that caused by the pollutants generated during the entire life cycle of the mesoporous $\mathrm{K}-\mathrm{Ag} / \mathrm{Co}_{3} \mathrm{O}_{4}$ catalyst.

(4) Power consumption is the main influencing factor impacting human health, and environmental or resource depletion. Therefore, it is particularly important to prepare the resource-saving catalyst by reducing power consumption, which can be realized by improving the production process of the catalyst and ameliorating the performance of equipment, especially high power consumption such as ovens and muffle furnaces. Throughout the production process, the equipment was kept running for several hours, and it is recommended to use frequency conversion equipment. Frequency conversion equipment can reduce the actual power consumption by reducing the frequency of the power supply and the actual running power of the equipment when the setting temperature is reached.

\section{Conclusion}

(1) Gas collection devices or purification devices are recommended to reduce the release of gaseous pollutants into 
the atmosphere.

(2) Mesoporous $\mathrm{K}-\mathrm{Ag} / \mathrm{Co}_{3} \mathrm{O}_{4}$ catalyst has a good environmental effect, which is industrially applicable.

(3) Whether it is health impact, environmental impact or resource depletion, electricity consumption is the main factor. Thus, it is necessary to improve the production process and use low-power equipment to reduce the environmental impact of the entire life cycle.

\section{Acknowledgements}

This study was supported by the National Key Research and Development Program foundation of China (grant No. 2016YFC0209201).

\section{References}

[1] Mishra, S., Weighting method for bi-level linear fractional programming problems. European Journal of Operational Research, 2007. 183(1): pp. 296-302.

[2] Santos, L. F.d. O. M., L. Osiro, and R. H. P. Lima, A model based on 2-tuple fuzzy linguistic representation and Analytic Hierarchy Process for supplier segmentation using qualitative and quantitative criteria. Expert Systems with Applications, 2017. 79: pp. 53-64.

[3] Shen, C. H., A comparison of principal components using TPCA and nonstationary principal component analysis on daily air-pollutant concentration series. Physica a-Statistical Mechanics and Its Applications, 2017. 467: pp. 453-464.

[4] Zhang, W., et al., Fuzzy Comprehensive Evaluation for the Industrial Application Potential of Circulating Fluidized Bed-Flue Gas Desulphurization. Journal of Engineering Thermophysics, 2015. 36(5): pp. 1130-1134.

[5] Harder, R., et al., Review of Environmental Assessment Case Studies Blending Elements of Risk Assessment and Life Cycle Assessment. Environ Sci Technol, 2015. 49(22): pp. 13083-93.

[6] Walser, T., et al., Prospective environmental life cycle assessment of nanosilver T-shirts. Environ Sci Technol, 2011. 45(10): pp. 4570-8.

[7] Hong, J. and X. Xu, Environmental impact assessment of caprolactam production - a case study in China. Journal of Cleaner Production, 2012. 27: pp. 103-108.

[8] Zhang, Y. and Y. Li, Pollution Situation of VOCs in Ambient Air and Research Progresses of VOCs Treatment Technologies. Environmental Protection of Chemical Industry, 2009. 29(5): pp. 411-415.

[9] Kaluž, L., et al., $\mathrm{CoMo} / \mathrm{ZrO}_{2}$ Hydrodesulfurization Catalysts Prepared by Chelating Agent Assisted Spreading. Procedia Engineering, 2012. 42: pp. 261-266.
[10] Liu, X., Y. Q. Han, and H. S. Jia, Pt-Rh-Pd Alloy Group Gauze Catalysts Used for Ammonia Oxidation. Rare Metal Materials and Engineering, 2017. 46(2): pp. 339-343.

[11] Bai, B. and J. Li, Positive Effects of $\mathrm{K}^{+}$Ions on Three-Dimensional Mesoporous $\mathrm{Ag} / \mathrm{Co}_{3} \mathrm{O}_{4}$ Catalyst for $\mathrm{HCHO}$ Oxidation. ACS Catalysis, 2014. 4(8): pp. 2753-2762.

[12] Nunez, P. and S. Jones, Cradle to gate: life cycle impact of primary aluminium production. International Journal of Life Cycle Assessment, 2016. 21(11): pp. 1594-1604.

[13] Lee, N., Tae, S., Gong, Y. and Roh, S. Integrated building life-cycle assessment model to support South Korea's green building certification system (G-SEED). Renewable \& Sustainable Energy Reviews, 2017. 76: pp. 43-50.

[14] Kiddee, P., R. Naidu, and M. H. Wong, Electronic waste management approaches: An overview. Waste Management, 2013. 33(5): pp. 1237-1250.

[15] Van der Velden, N. M., K. Kuusk, and A. R. Koehler, Life cycle assessment and eco-design of smart textiles: The importance of material selection demonstrated through e-textile product redesign. Materials \& Design, 2015. 84: pp. 313-324.

[16] Li, Q., et al., Nanocellulose Life Cycle Assessment. ACS Sustainable Chemistry \& Engineering, 2013. 1(8): pp. 919-928.

[17] Guillet, C., et al., Episodic high $\mathrm{CH}_{4}$ emission events can damage the potential of soils to act as $\mathrm{CH} 4$ sink: evidence from 17 years of $\mathrm{CO}_{2}$ enrichment in a temperate grassland ecosystem, in Agriculture and Climate Change - Adapting Crops to Increased Uncertainty, D. Edwards and G. Oldroyd, Editors. 2015. pp. 208-209.

[18] Sharma, M., et al., Role of atmospheric ammonia in the formation of inorganic secondary particulate matter: A study at Kanpur, India. Journal of Atmospheric Chemistry, 2007. 58(1): pp. 1-17.

[19] Emiroglu, A. O., Investigation of $\mathrm{NO}_{\mathrm{x}}$ reduction activity of $\mathrm{Rh} / \mathrm{ZnO}$ nanowires catalyst. Atmospheric Pollution Research, 2017. 8(1): pp. 149-153.

[20] Fugiel, A., et al., Environmental impact and damage categories caused by air pollution emissions from mining and quarrying sectors of European countries. Journal of Cleaner Production, 2017. 143: pp. 159-168.

[21] Audenaert, A., S. H. D. Cleyn, and M. Buyle, LCA of low-energy flats using the Eco-indicator 99 method: Impact of insulation materials. Energy \& Buildings, 2012. 47(4): pp. 68-73.

[22] Feng, C. and X. Q. Ma, The energy consumption and environmental impacts of a color TV set in China. Journal of Cleaner Production, 2009. 17(1): pp. 13-25.

[23] Zeng-ying, L. and M. A. Xiao-qian, Life Cycle Assessment on Selective Catalytic Reduction Flue-gas Denitrification. Proceedings of the Chinese Society of Electrical Engineering, 2009. 29(17): pp. 63-69. 